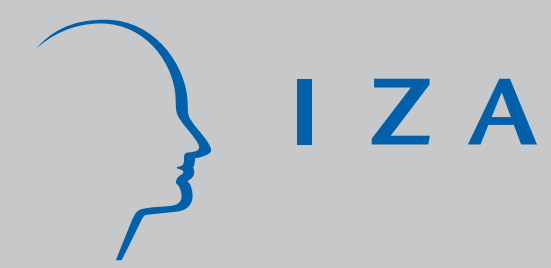

IZA DP No. 978

How Does the Unemployment Insurance System Shape the Time Profile of J obless Duration?

J ohn T. Addison

Pedro Portugal

J anuary 2004 


\title{
How Does the Unemployment Insurance System Shape the Time Profile of Jobless Duration?
}

\author{
John T. Addison \\ University of South Carolina \\ and IZA Bonn \\ Pedro Portugal \\ Banco de Portugal and Universidade Nova de Lisboa
}

Discussion Paper No. 978
January 2004

IZA

P.O. Box 7240

D-53072 Bonn

Germany

Tel.: +49-228-3894-0

Fax: +49-228-3894-210

Email: iza@iza.org

This Discussion Paper is issued within the framework of IZA's research area Welfare State and Labor Market. Any opinions expressed here are those of the author(s) and not those of the institute. Research disseminated by IZA may include views on policy, but the institute itself takes no institutional policy positions.

The Institute for the Study of Labor (IZA) in Bonn is a local and virtual international research center and a place of communication between science, politics and business. IZA is an independent, nonprofit limited liability company (Gesellschaft mit beschränkter Haftung) supported by Deutsche Post World Net. The center is associated with the University of Bonn and offers a stimulating research environment through its research networks, research support, and visitors and doctoral programs. IZA engages in (i) original and internationally competitive research in all fields of labor economics, (ii) development of policy concepts, and (iii) dissemination of research results and concepts to the interested public. The current research program deals with (1) mobility and flexibility of labor, (2) internationalization of labor markets, (3) welfare state and labor market, (4) labor markets in transition countries, (5) the future of labor, (6) evaluation of labor market policies and projects and (7) general labor economics.

IZA Discussion Papers often represent preliminary work and are circulated to encourage discussion. Citation of such a paper should account for its provisional character. A revised version may be available on the IZA website (www.iza.org) or directly from the author. 
IZA Discussion Paper No. 978

January 2004

\section{ABSTRACT \\ How Does the Unemployment Insurance System Shape the Time Profile of Jobless Duration?}

This paper examines the effects of unemployment insurance on escape rates from unemployment using data from the 1998 Displaced Worker Survey. Transitions from unemployment to employment are modeled using a flexible representation of the baseline hazard function and allowing for discrete changes through time in the effects of unemployment insurance benefits, as well as those of the other covariates. The impact of unemployment insurance is also modeled using a time-varying benefits measure, namely, time to exhaustion of benefits. Potential biases stemming from reverse causation and unobserved individual heterogeneity are accommodated. Both approaches render transparent the major disincentive effects of access to benefits on re-employment rates while also providing evidence of time-varying effects of other regressors.

JEL Classification: J64, J65

Keywords: unemployment benefits, unemployment duration, time-varying coefficients/ regressors

Corresponding author:

John T. Addison

Department of Economics

Moore School of Business

University of South Carolina

1705 College Street

Columbia, SC 29208

USA

Tel.: +1 8037774608

Fax: +1 8037776876

Email: ecceaddd@moore.sc.edu 


\section{Introduction}

In the conventional search model, unemployment insurance elevates the reservation wage and lengthens the duration of the unemployment spell. Once we allow for finite benefits, reservation wages should fall with the approach of benefit exhaustion. As a result of the decline in the value of remaining unemployed, and increased search intensity, escape rates should rise monotonically (Mortensen, 1977). (Indeed, even if workers are not engaged in productive search - as in the static labor-leisure model - a clustering of observations around the exhaustion point is predicted.) After benefit exhaustion, a cet. par. constant hazard rate is indicated. ${ }^{1}$

Despite the insights of search theory, only a handful of studies have allowed for a time-varying effect of benefits on unemployment duration. The classic study is by Meyer (1990), who deploys time-to-exhaustion splines in analyzing administrative data for U.S. males from twelve states, 1978-83 (see also Katz and Meyer, 1990). ${ }^{2}$ Meyer reports that the probability of escaping from unemployment rises dramatically shortly before exhaustion: from 6 to 2 weeks before exhaustion the hazard increases 67 percent, and one week away from exhaustion the hazard increases by an additional 97 percent (though the hazard is flat between 41 to 6 weeks). Other U.S. studies have examined the time-varying effect of benefits in terms of a competing risks model where the choice is that between full- and part-time work (McCall, 1996, 1997) and indirectly via tests of the proportionality assumption (McCall, 1994). Another has examined the time-varying effects of a reemployment bonus (and recall expectations) on joblessness (Anderson, 1992). Although there is some dispute about whether or not benefit exhaustion is the source of observed spikes in escape rates at 26 (or 39) weeks, constraining benefits to 
have the same effects on the hazard function at each point in the unemployment spell is clearly contraindicated in the data. ${ }^{3}$

There is almost no modern British evidence, but in an analysis U.K. Department of Health and Social Security data for 1978/79, Narendranathan and Stewart (1993) report more muted effects of unemployment income, comprising earnings and need supplemented unemployment benefits, on unemployment duration. Specifically, their basic specification indicates that income while unemployed does not have an effect on joblessness beyond the twelfth week of unemployment, rising to twenty weeks with allowance for unobserved individual heterogeneity. These intervals are well below the 12-month national insurance benefit then payable.

In the present treatment, we use very recent U.S. data on displaced workers that has a number of distinct advantages over the earlier literature. Thus, in contrast to administrative data it contains information on both recipient and nonrecipients of unemployment insurance benefits. The disadvantages of the data used by Meyer (1990) and others are that they refer to recipients alone and are moreover only observed while benefits are paid, at which point they are censored. And unlike earlier U.S. displaced worker data the reported jobless duration is not contaminated by multiple spells of unemployment and there is no top coding of joblessness.

We shall employ a flexible representation for the baseline hazard function and allow the effect of unemployment benefits to vary before, at, and after exhaustion of benefits (either 26 or 30 weeks) - and, in a new departure, we shall allow the effects of the other covariates to vary over the jobless spell. In a final specification, we replace the unemployment benefits variables with a time-to-exhaustion measure while allowing for a 
potential spike at the point of exhaustion. Throughout, care is taken to avoid the problem of reverse causation, while accounting for omitted heterogeneity.

The plan of the paper is as follows. Section II introduces the flexible representation of the baseline hazard and the manner of the incorporation of time-varying effects. Section III reviews the data and indicates how we dealt with the problem of reverse causation. Section IV details the empirical findings. A brief summary concludes.

\section{Model Specification}

Consider a time axis that is divided into $M$ intervals by points $k_{1}, k_{2}, \ldots, k_{m-1}$. Assuming a conventional piecewise-constant proportional hazards function, we can write

$$
h_{i}(t \mid x)=\mathrm{e}^{x_{i} \beta+\lambda_{m}} \quad k_{\mathrm{m}-1} \leq t<k_{\mathrm{m}} \quad m=1, \ldots, M
$$

where $x$ is a vector of explanatory variables for worker $i, \beta$ identifies the regression coefficients, and $\lambda_{m}$ is the exponential parameter for the $m$ interval (Prentice and Gloeckler, 1978; Lancaster 1990).

We will first consider the specification of the impact of unemployment benefits on the hazard rate. As discussed earlier, we want to identify the role of unemployment insurance benefits (UB) before, at, and after the point of exhaustion. For this purpose, we expand the hazard model as follows

$$
\begin{aligned}
h_{i}\left(t \mid x_{i}, U B\right)= & \exp \left\{\mathrm{x}_{\mathrm{i}} \beta+\lambda_{m}+\right. \\
& \left.\alpha_{1}\left[U B_{i} I\left(4 \leq t<t^{*}\right)\right]+\alpha_{2}\left[U B_{i} I\left(t=t^{*}\right)\right]+\alpha_{3}\left[U B_{i} I\left(t>t^{*}\right)\right]\right\},
\end{aligned}
$$

where $I$ denotes the indicator function and $t^{*}$ is the maximum potential duration of unemployment benefits. Proceeding in this way, the $\alpha_{1}$ parameter gives the impact of 
unemployment benefits prior to exhaustion, $\alpha_{2}$ denotes their effect at the point of exhaustion, while $\alpha_{3}$ picks up any post-exhaustion influence. In order to avoid misrepresenting the effect of benefits, we must not allow short durations (of less than 4 weeks) to influence the estimation of parameter $\alpha_{1}$. Apart from the existence of waiting periods (of typically one week), it is well known that workers with very short durations of unemployment have lower take-up rates.

Alternatively, we can also allow for increasing hazard rates as the expiration of benefits approaches

$$
h_{i}\left(t \mid x_{i}, U B\right)=\exp \left\{\mathrm{x}_{\mathrm{i}} \beta+\lambda_{m}+\delta_{1}\left[U B_{i} I(t>4)\left(t-t^{*}\right) I\left(t<t^{*}\right)\right]+\delta_{2}\left[U B_{i} I\left(t=t^{*}\right)\right]\right\} .
$$

Moreover, because it is possible that the time-varying effects of unemployment benefits may capture time-varying effects of other covariates, in both approaches we will also need to allow for time-varying coefficients in respect of these regressors as well. To this end, it seems reasonable to set breakpoints alternatively at 4 and 26 weeks. Taking our first specification, for example, we re-specify the hazard function as

$$
\begin{aligned}
h_{i}\left(t \mid x_{i}, U B\right)= & \exp \left\{[I(t<4)] \mathrm{x}_{\mathrm{i}} \beta_{1}+[I(t \geq 4)] \mathrm{x}_{\mathrm{i}}\left(\beta_{1}+\beta_{2}\right)+\lambda_{m}+\right. \\
& \left.\alpha_{1}\left[U B_{i} I\left(4 \leq t<t^{*}\right)\right]+\alpha_{2}\left[U B_{i} I\left(t=t^{*}\right)\right]+\alpha_{3}\left[U B_{i} I\left(t>t^{*}\right)\right]\right\}
\end{aligned}
$$

and proceed similarly for a cutoff at 26 weeks. Here the $\beta_{1}$ coefficient vector provides the impact of the regressors during the first time period and the $\beta_{2}$ vector gives the change in the impact of the regressors in the second period.

Turning to the issue of implementation, we will employ a piecewise-constant specification, with jobless durations grouped into 16 intervals. (As noted below, our unemployment measure is weekly spell length, which is no longer top coded.) The choice 
of 16 intervals is partially dictated by the relative frequency of the observations within each (weekly) cell. Specifically, the intervals are weekly observations up to and including week 4 , followed by 11 intervals of 4 weeks up to and including week 48, and with the balance of the observations constituting the final interval.

In order to estimate the model, the survivor function has first to be defined. For the $m$ interval this can be can expressed as

$$
S\left(k_{m}\right)=\exp \left[-\sum_{j=1}^{m} \mathrm{~h}_{\mathrm{j}}\right]=\exp \left[-\Lambda\left(k_{m}\right)\right]
$$

where $\Lambda\left(k_{m}\right)$ is the integrated hazard function.

We can incorporate unobserved individual heterogeneity through the inclusion of a multiplicative error term $v$ in the hazard function. For present purposes, we will select a conventional parametric form for $v$, namely, the gamma distribution with unit mean and variance $\sigma^{2}$. This choice allows us use a simple closed form for the survival function (Lancaster, 1990)

$$
S\left(k_{m}\right)=\left[1+\sigma^{2} \Lambda\left(k_{m}\right)\right]^{-\frac{1}{\sigma^{2}}} .
$$

The likelihood contribution for an individual who exits at interval $m$ is given by $S\left(k_{m}\right)$ $S\left(k_{m-1}\right)$ and for an individual whose duration is censored at $m$ by $S\left(k_{m-1}\right)$.

In general, the likelihood function can be expressed

$$
L_{i}=\prod_{m=1}^{M}\left[\left(S_{i}\left(k_{m-1}\right)-S_{i}\left(k_{m}\right)\right)^{\delta_{i}}\left(S_{i}\left(k_{m-1}\right)^{1-\delta_{i}}\right]^{\delta_{m_{i}}}\right.
$$

where $\delta_{i}$ identifies an uncensored duration and $\delta_{m_{i}}$ equals 1 if the individual's duration falls in the $m$ interval, 0 otherwise. ${ }^{4}$ 


\section{Data}

The data used in this inquiry are taken from the nationally representative, three-year retrospective Displaced Worker Supplement to the February 1998 Current Population Survey. The dataset - and changes in the survey including the wording of the core displacement question and the recall period over which information on job loss is recorded - are well described elsewhere (see, for example, Kletzer, 1998; Farber, 2003), so that only brief introductory remarks are required here. The DWS has been conducted biennially since 1984. It contains information on the nature of the lost job and subsequent joblessness for workers displaced by reason of plant closure, slack work, or abolition of shift or position. Such data can be supplemented by extensive information on the personal characteristics of the worker contained in the parent CPS.

The DWS has a number of advantages over administrative data. The principal deficiency of administrative data is that there is no counterfactual, with the result that it is difficult to tell whether rising hazards observed at or around the point of benefit exhaustion truly reflect the impact of impending or actual benefit exhaustion. As we have noted in passing, earlier work using the DWS indicates that the escape rates of not just recipients but also nonrecipients are characterized by humps at 26 and 39 weeks, the later representing the end of 'extended' benefits (Fallick, 1991, p. 230). Added to which, there is also the problem that all duration observations using administrative data are censored at benefit expiration. In sharp contrast, the DWS data allow us to observe what happens before, at, and after the exhaustion of benefits.

There are inevitably some shortcomings of the DWS data. Thus, retrospective data are subject to recall bias - individuals experiencing displacement in past years may 
be more likely to understate their jobless duration than are more recent job losers - and respondents are prone to round (to months and quarters) their reported spells of unemployment. Beginning with the 1994 survey, however, the period over which job loss is measured has been reduced from five to three years, which should reduce the recall bias problem. Also, our use of a flexible, piecewise constant representation of the baseline hazard function should serve to accommodate the rounding problem.

If the former two problems are fairly easily dealt with, a third is potentially more difficult. The DWS data merely identify whether the respondent is a recipient or nonrecipient of unemployment benefits. An unknown number of those classified as 'nonrecipients' may in fact have been eligible for benefits but failed to collect them because they expected to find employment within an interval corresponding to the waiting times and filing delays associated with drawing benefits. In other words, receipt of benefits is not the same as eligibility for benefits and may depend on the duration of a spell. (Note that administrative data are subject to the selfsame problem.) Treating nonrecipients as noneligibles may be expected to upwardly bias the effect of unemployment benefits on joblessness. This problem of reverse causation is handled by making our estimation procedure 'blind,' that is, we do not consider the effect of unemployment benefits during the first four weeks of the unemployment event but continue to use the duration data. This procedure is better than the alternative of simply truncating the data at four weeks, albeit with appropriate accommodation for sample truncation. ${ }^{5}$

Use of the 1998 DWS has some advantages over its precursors. The definition of unemployment in the first two DWS surveys admits of multiple spells of joblessness. 
Since the 1988 survey the measure of unemployment refers to the length of the single spell of joblessness that followed the displacement event and resulted in reemployment. To be sure, the definition still does not require the unemployed individual to be engaged in active search so that this single spell may include intervals of suspended job search/withdrawal but it no longer includes multiple spells of joblessness. A more recent innovation is that the DWS unemployment data are no longer top coded (at 99 weeks of joblessness). The only source of right censoring in our data stem from our inclusion (via the CPS) of those individuals who failed to find work after displacement but who were nevertheless economically active as of the survey date. Such censoring is explicitly accommodated in the likelihood function given in equation (7).

Two pieces of information were derived from other sources. First, data on maximum benefit entitlement was compiled from the Green Book Overview of Entitlement Programs, published annually by the Committee of Ways and Means of the U.S. House of Representatives. These data were used to construct our BEFORE, AT, and AFTER phases of benefit receipt and the time-varying regressor TIMEX, or time to exhaustion of benefits, which is measured as maximum benefit entitlement less elapsed duration of unemployment. As a practical matter, it emerged that only two states had maximum durations greater than 26 weeks over the sample period. These were Massachusetts and Washington, each with a maximum entitlement of 30 weeks. Second, the DWS data were supplemented with BLS data on (average annual) state unemployment rates at the year of displacement.

Although we included those who wanted but never found employment after losing their jobs - as well as those individuals who transitioned directly into reemployment 
without any intervening spell of joblessness - we excluded individuals who were not economically active at the time of the survey. Further, because the nature of displacement is not well defined for certain individuals and sectors, those employed part time and in agriculture at the point of displacement were also excluded, as were those aged less than 20 years and above 61 years as of February 1998. These restrictions yielded a sample of 2,762 individuals. Descriptive information on the sample is provided in the appendix table.

(Figure 1 near here)

Finally, to set the scene for our cet. par. analysis, Figure 1 charts the differences in the empirical (Life-Table) hazard rates of unemployment benefit nonrecipients and recipients. As can be seen, the escape rates of nonrecipients remain considerably higher than those of recipients even after the first four weeks of the jobless spell. For these initial weeks it is likely that the line of causation does indeed run from duration to unemployment benefit status. At week 26, however the escape rates of recipients pick up and well exceed those of nonrecipients. And thereafter, as the polynomial curve fitted to the empirical hazard makes clearer, the escape rates of recipients seemingly continue to exceed those of nonrecipients.

\section{Findings}

Results of fitting the piecewise constant hazards model allowing for time-varying effects of unemployment benefits are given in Table 1. It will be recalled that the effects of benefits are calculated before (comprising an interval from the fifth week of joblessness to week 25 or 29 according to the individual's state), at (week 26 or 30), and after (week

27 or 31 onward) their expiration. The unemployment benefits variable and other 
regressors capture factors that influence the reservation wage and/or the arrival rate of job offers. In the first column of table the effects of the other regressors are constrained not to vary through time. The remaining columns allow for a distinct break in the effects of the latter at 4 weeks and 26 weeks, respectively.

(Table 1 near here)

Beginning with the most parsimonious specification, it can be seen that, prior to benefit exhaustion, the escape rates of recipients are 37.8 percent lower than those of recipients. At expiration, however, the hazard rate of former recipients is now more than twice that of nonrecipents (2.54 times to be precise), and it remains around 27 percent higher over the balance of the employment event, although the after-exhaustion point estimate is less well determined.

As far as the other regressors are concerned, the worker's age (AGE) and tenure (TENURE) with the firm at the point of displacement are associated with significantly lower escape rates from joblessness. (The statistical insignificance of the negative coefficient on measure of labor market slack - the displacement-contemporaneous state unemployment rate $(U R)$ - is commented on below.) The effect of the tenure variable most probably captures the elevated reservation wages of long-serving workers, while the two other arguments proxy the reduced arrival rate of job offers with age and higher labor market slack. In contrast, years of education (SCHOOLING), race (WHITE) and marriage in the case of males (MARRIED) are each associated with more rapid job finding after displacement. More educated workers might be expected to have higher escape rates because of their greater search efficiency, higher opportunity cost of staying unemployed, and generally better job prospects. Similarly, the result for race is familiar and captures 
the poorer opportunities facing blacks as a result of both objective and discriminatory factors. The result for married males presumably picks up a household head effect, and thus likely reflects the higher opportunity cost of unemployment for married males and their greater search intensity. Note there is virtually no effect of marriage on female escape rates, while single males have marginally lower escape rates than the omitted category of single females.

But although the effects of formal advance notice of impending displacement (NOTICE) - defined as written notice of at least two months - and job loss by reason of plant closure (CLOSE) are also positive they are not statistically significant. It is often argued in the displacement literature that the compositional or labor quality implications of plant closings - all workers are 'canned' when a plant closes its doors rather than a subset of workers (selected by management) in the case of slack work or abolition of shift or position - and the enhanced search facilitated by advance notice should each lead to lower joblessness. Yet, as we have seen, neither effect is well determined. The same is true of union membership (UNION) which might also connote possession of an informational edge in the labor market. With one exception, the inclusion of state dummies, introduced in order to accommodate state differences in unemployment insurance rules (other than maximum potential duration of benefits), does not affect the precision of the regression coefficient estimates and in particular the measured impact of unemployment benefits. That one exception is the state unemployment rate in the year of displacement $(U R)$, which is no longer statistically significant.

The information in the next three columns of Table 1 is for a specification that allows for a discrete change in the effect of the non- $U B$ covariates at four weeks. 
Although taken from a single equation, the presentation of 'separate' columns for joblessness of $\leq 4$ weeks and $>4$ weeks in respect of these other regressors helps identify shifts in effect. Beginning with the effects of benefit recipiency, however, we obtain virtually identical coefficient estimates for each of the three phases - before, at, and after exhaustion of benefits, respectively - as in the first column of the table. In each case, however, the coefficient estimates are slightly better determined than before. Overall, the likelihood ratio statistic is 16.6 , below the critical value of the chi-square distribution with 11 degrees of freedom of 19.68 (for a 5 percent level of significance).

As far as the other variables are concerned, it can be seen that statistically significant changes in the coefficient estimates (after 4 weeks) are confined to just three arguments: NOTICE, AGE, and TENURE. In the case of the first variable, it appears that the impact of lengthy written notice is confined to the first few weeks of joblessness: the change in the coefficient estimate after 4 weeks is both opposite in sign and larger in absolute magnitude than the value prior to that. (Recall that the coefficients are additive.) As for older workers, there is some indication that the (deleterious) impact of $A G E$ is also short-lived, at least in part. On the other hand, the effects of tenure in reducing escape rates seem to grow with time.

Use of a different, 26-week breakpoint, shown in the last three columns of Table 1, produces few surprises. Thus, the results for the three phases of unemployment benefits are not materially affected, and there are just two statistically significant changes in the case of the other covariates. For both SCHOOLING and AGE there is every indication that the positive effects of the former and the negative effects of the latter do not continue beyond the twenty-sixth week of joblessness. That is to say, in each case, the 
opposing effects are a wash. Finally, we note that the likelihood ratio statistic is now even lower than before, at 9.86 .

(Table 2 near here)

In Table 2 we substitute a time-varying unemployment benefit regressor for the discrete measure, although we still allow for a spike in escape rates at exhaustion of benefits. It will be recalled that our time to exhaustion of benefits measure, TIMEX, represents the difference between an individual's elapsed duration of unemployment and the maximum duration of benefits in his or her state. It is anticipated that its coefficient estimate will be negative, meaning that the escape rates of recipients will fall further below those of recipients the greater the interval to benefit exhaustion, or equivalently that the disparity between the two groups will steadily narrow with the progression of the jobless spell. ${ }^{6}$

As before, the first column of the table provides results for the most parsimonious specification. It can be seen that one week away from benefit exhaustion the escape rates of recipients are just 3.3 percent below those of nonrecipients. But 10 weeks before exhaustion the escape rates of recipients are only two-thirds those of recipients difference and at 20 weeks just one-third of those of recipients. Note that the coefficient estimate for TIMEX is highly statistically significant. Also note that at exhaustion the escape rate of recipients spikes upward, such that it is now more than twice that of their nonrecipient counterparts; specifically, it is 2.43 times that of nonrecipients, almost the same as the corresponding estimate from the first column of Table 1.

Not surprisingly, the point estimates of the other regressors in the first column of Table 2 are almost identical to those reported in Table 1. Equally, there are no surprises 
when we allow for the discrete changes in the effects of the other regressors at 4 and 26 weeks. In other words, the balance of Table 2 confirms the absence of persistence in the advantages of greater education and longer notice and in the disadvantages of age.

But the main result is that use of a time-varying unemployment benefits regressor usefully complements our earlier analysis of the time-varying effects of unemployment insurance in suggesting that potential benefit duration has significant behavioral effects on worker job finding .

Finally, we should note that the variance parameter of the gamma distribution converged toward zero in all specifications. We interpret this outcome to mean that unobserved individual heterogeneity is not a serious cause for concern in the present exercise, given the flexibility of the baseline hazard function and the set of regressors employed. This interpretation is further reinforced by the fact that in almost all cases this eventuated only after inclusion of the state dummies.

\section{Conclusions}

Our analysis has demonstrated that the effects of unemployment insurance on jobless duration in the wake of job displacement are real and not an artifact of the data resulting from either heaping (i.e. respondent rounding) or unobserved individual heterogeneity. Receipt of unemployment benefits is associated with a marked reduction in escape rates prior to their exhaustion. Thus, the escape rates of recipients over this interval are roughly 40 percent lower than those of their nonrecipients counterparts. Note that this estimate is unlikely to contaminated by a reverse line of causation running from duration to benefit receipt precisely because we did not allow benefits to have any effect during the first month of unemployment experience. At or around benefit exhaustion, the escape rates of 
recipients are more than twice those of nonrecipients, even if comparatively few spells last long enough to be affected by the spike. (After exhaustion, the escape rates of former recipients continue to be greater than those of nonrecipients but the benefit effect is less precisely estimated.) Our major finding is reinforced when we substitute potential benefit duration for unemployment benefit status. That is, we observe a steady reduction - of 3.3 percent a week - in the relative escape rates of recipients the further away is benefit exhaustion. Since we are controlling for both unobserved heterogeneity and state fixed effects, we are confident that we are uncovering behavioral effects. This result is underscored by the finding from other work using the DWS that longer search does not lead to a material improvement in postdisplacement wages (e.g. Addison and Blackburn, 2000).

Our broad findings are very much in line with results from other studies in a very sparse literature. But, to repeat, the advantages if the present study are fourfold. First, unlike analyses using administrative data, we have the counterfactual of nonrecipients behavior while our data on recipient duration are not censored when benefits run out. Second, unlike work using information on displaced individuals, our data reflect material improvements in the DWS through time, such as duration data that are no longer right censored or that include multiple spells of joblessness. Third, unlike studies based on both types of information, we examine both males and females and find among other things that marriage does not greatly affect the behavior of females. Finally, our model allows for and reports evidence favoring time-varying effects of non-UI regressors.

Policy is as ever a more difficult consideration. We would resist the interpretation that our findings support a reduction in the periodicity of benefits. This strategy is likely 
more appropriate for European countries than the United States. By the same token, they arguably do point to initiatives that stimulate more rapid job finding on the part of the great mass of the insured unemployed population. Obvious measures here include job search assistance allied to more stringent application of the job search test and further experimentation with reemployment bonuses. 


\section{Endnotes}

1. However, Meyer (1990, p. 758) notes that this constant post-exhaustion hazard rate may lie above or below the exhaustion hazard according to whether leisure and income are complements or substitutes, repectively.

2. The earliest study is Nickell's (1979) analysis of 426 males drawn from the British 1972 General Household Survey. He allows the effect of the unemployment insurance (UI) replacement rate on escape rates to change with spell duration, and is able to reject the null of a constant effect of the UI measure on the hazard.

3. In particular, Fallick (1991) has argued that such spikes characterize the hazard rates of recipients and nonrecipients alike. Using data from the January 1984 Displaced Worker Survey, he reports that shortly before and shortly after benefits commonly expire the cet. par. effect of unemployment insurance is statistically insignificant. He speculates that the spikes are a function of rounding on the part of both insured and uninsured respondents (on which, see Poterba and Summers, 1984; Sider, 1984). Note that Fallick reports time varying effects of UI on escape rates for those displaced workers who change industry.

4. As a robustness check, we also employed a Cox partial likelihood estimator. The advantage of this approach is of course that it can equally well accommodate timevarying effects of the covariates without the need to specify a parametric form for the baseline hazard. In the event, the estimation results were remarkably similar to the ones presented below for the piecewise-constant estimator.

5. Using an eight-week knot points did not appreciably alter our results: the reduction in the hazard was still large and statistically significant, albeit a bit smaller in absolute magnitude.

6. This specification does not allow for differences between benefit recipients and nonrecipients after exhaustion. 


\section{References}

Addison, John T. and McKinley L. Blackburn, "Unemployment Insurance and Postunemployment Earnings," Labour Economics 7 (January 2000): 21-53.

Anderson, Patricia M., "Time-varying Effects of Recall Expectation, a Reemployment Bonus, and Job Counseling on Unemployment Durations,' Journal of Labor Economics 10 (January 1992): 98-115.

Fahrmeir, Ludwig and Gerhard Tutz, Multivariate Statistrical Modelling Based on Generalized Linear Models, Berlin and New York: Springer Verlag, 1994.

Fallick, Bruce Chelimsky, "Unemployment Insurance and the Rate of Re-Employment of Displaced Workers," Review of Economics and Statistics 73 (May 1991): 228-235.

Farber, Henry S., "Job Loss in the United States, 1981-2001," Working Paper No. 471, Princeton University Industrial Relations Section, January 2003.

Katz, Lawrence F. and Bruce D. Mayer, "The Imapct of Potential Duration of Unemployment Benefits on the Duration of Unemployment," Journal of Public Economics 41 (February 1990): 45-72.

Kletzer, Lori G., "Job Displacement," Journal of Economic Perspectives 12 (Winter 1998): 115-136.

Lancaster, Tony, The Econometric Analysis of Transition Data, Cambridge: Cambridge University Press, 1990.

McCall, Brian P., 'Testing the Proportional Hazards Assumption in the Presence of Unmeasured Heterogeneity," Journal of Econometrics 9 (July-September 1994): 321334. 
McCall, Brian P., "Unemployment Insurance Rules, Joblessnesss, and Part-Time Work," Econometrica 64 (May 1996): 647-682.

McCall, Brian P., "The Determinants of Full-Time versus Part-Time Reemployment following Job Displacement,” Journal of Labor Economics 15 (October 1997): 714-734.

Meyer, Bruce D., "Unemployment Insurance and Unemployment Spells,” Econometrica 58 (July 1990): 757-782.

Mortensen, Dale T. "Unemployment Insurance and Job Search Decisions," Industrial and Labor Relations Review 30 (July 1977): 505-517.

Narendranathan, Wiji and Mark B. Stewart, "How Does the Benefit Effect Vary as Unemployment Spells Lengthen? Journal of Applied Econometrics 8 (October-December 1993): 361-381.

Nickell, Stephen J., Estimating the Probability of Leaving Unemployment," Econometrica 47 (September 1979): 1249-1266.

Portugal, Pedro and John T. Addison, "Problems of Sample Construction Bias in Studies of the Effects of Unemployment Insurance on Unemployment Duration," Industrial and Labor Relations Review 43 (April 1990): 463-477.

Poterba, James and Lawrence Summers, "Survey Response Variation in the Current Population Survey," Monthly Labor Review 43 (March 1984): 37-43.

Prentice, Ross and L.A. Gloeckler, "Regression Analysis of Grouped Survival Data with Application to Breast Cancer Data," Biometrics 34 (March 1978): 57-67.

Sider, Hal, "Unemployment Duration and Incidence, 1968-82," American Economic Review 75 (June 1985): 465-472. 
Figure 1: Differences in the Empirical Hazard Rates of UB Nonrecipients and Recipients

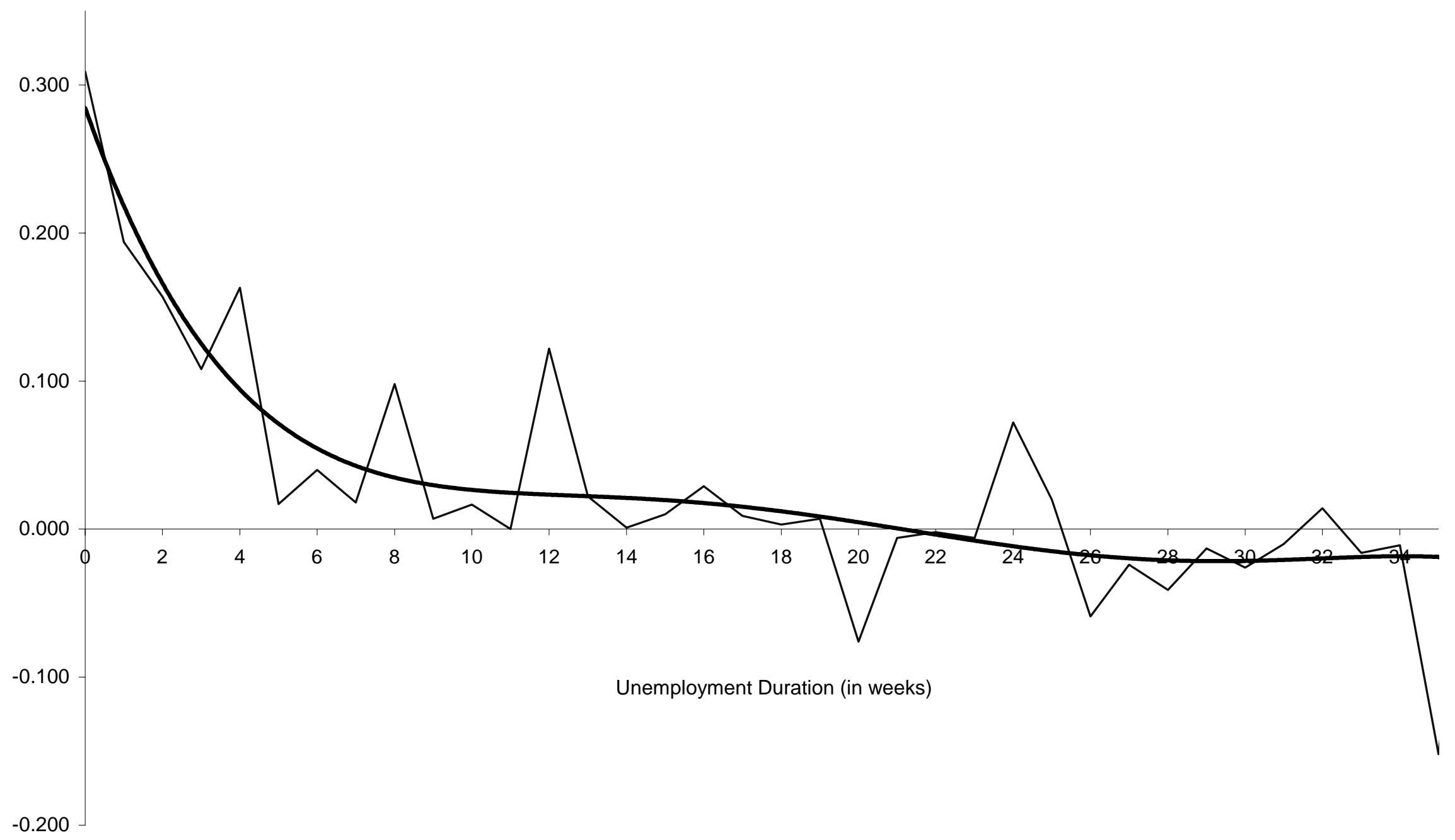


Table 1: The Determinants of Unemployment Duration with Time-Varying Effects for UB and the Non-UB Regressors, Piecewise-Constant Hazards Specification

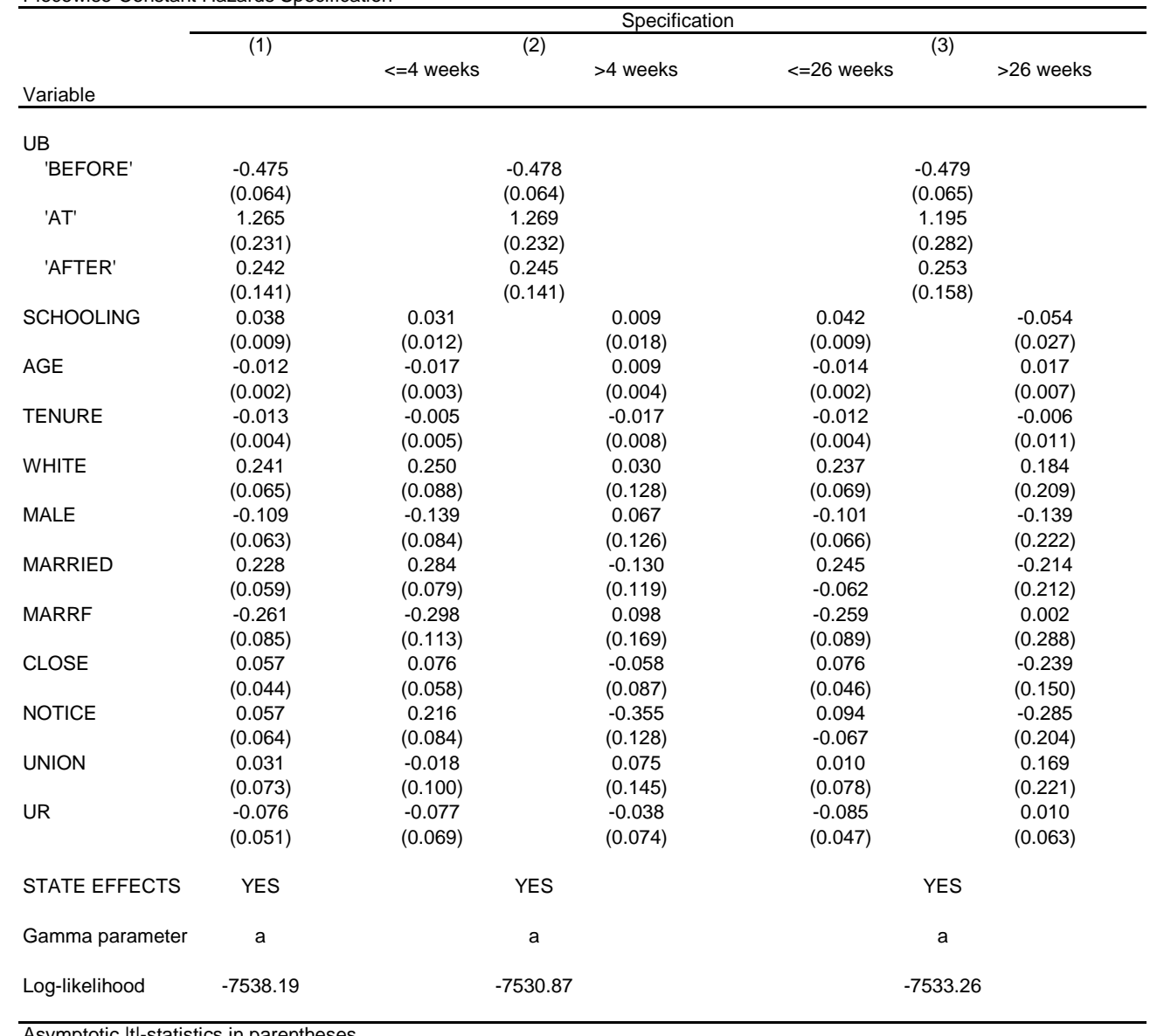

Asymptotic |t|-statistics in parentheses

Notes: The non-UB independent variables are SCHOOLING, years of schooling completed; AGE, age at time of displacement; TENURE, years of tenure with former employer; WHITE, dummy variable for white; MALE, dummy variable for male; MARRIED, dummy variable for married, MARRF, dummy variable for married female, CLOSE, dummy variable for job loss by reason of plan closing; NOTICE, dummy variable for written notice of at least 2 months; UNION, dummy variable for union member at time of job loss, UR, state unemployment rate at time of job loss. For unemployment beneft recipients, 'BEFORE' gives the interval before AFTER' is the post ax la, for week 4 up lo week 26/30; 'AT 'is the poin 
Table 2: The Determinants of Unemployment Duration with a Time-Varying UB Regressor, and Time-Varying Effects for the Other Regressors, Piecewise-Constant Hazards Specification

\begin{tabular}{|c|c|c|c|c|c|}
\hline \multirow{3}{*}{ Variable } & \multicolumn{5}{|c|}{ Specification } \\
\hline & \multirow[t]{2}{*}{ (1) } & \multicolumn{2}{|r|}{ 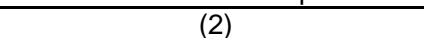 } & \multicolumn{2}{|c|}{ (3) } \\
\hline & & $<=4$ weeks & $>4$ weeks & $<=26$ weeks & $>26$ weeks \\
\hline \multicolumn{6}{|l|}{ UB } \\
\hline \multirow[t]{2}{*}{ TIMEX } & -0.034 & \multirow{2}{*}{\multicolumn{2}{|c|}{$\begin{array}{l}-0.034 \\
(0.004)\end{array}$}} & \multirow{2}{*}{\multicolumn{2}{|c|}{$\begin{array}{l}-0.034 \\
(0.004)\end{array}$}} \\
\hline & $(0.004)$ & & & & \\
\hline \multirow[t]{2}{*}{ 'AT' } & 1.234 & \multicolumn{2}{|c|}{1.235} & \multicolumn{2}{|c|}{1.366} \\
\hline & $(0.220)$ & \multicolumn{2}{|c|}{$(0.220)$} & \multicolumn{2}{|c|}{$(0.277)$} \\
\hline \multirow[t]{2}{*}{ SCHOOLING } & 0.039 & 0.032 & 0.010 & 0.042 & -0.047 \\
\hline & $(0.009)$ & $(0.012)$ & $(0.018)$ & $(0.009)$ & $(0.027)$ \\
\hline \multirow[t]{2}{*}{ AGE } & -0.012 & -0.016 & 0.009 & -0.014 & 0.020 \\
\hline & (0.002) & $(0.003)$ & $(0.004)$ & (0.002) & $(0.007)$ \\
\hline \multirow[t]{2}{*}{ TENURE } & -0.013 & -0.005 & -0.014 & -0.012 & -0.005 \\
\hline & $(0.004)$ & (0.005) & $(0.008)$ & $(0.004)$ & $(0.011)$ \\
\hline \multirow[t]{2}{*}{ WHITE } & 0.242 & 0.252 & 0.031 & 0.237 & 0.197 \\
\hline & $(0.065)$ & $(0.088)$ & $(0.128)$ & $(0.069)$ & $(0.209)$ \\
\hline \multirow[t]{2}{*}{ MALE } & -0.105 & -0.298 & 0.102 & -0.104 & -0.078 \\
\hline & $(0.063)$ & $(0.113)$ & $(0.169)$ & $(0.066)$ & $(0.220)$ \\
\hline \multirow[t]{2}{*}{ MARRIED } & 0.230 & 0.285 & -0.129 & 0.252 & -0.254 \\
\hline & $(0.059)$ & $(0.079)$ & $(0.119)$ & -0.062 & $(0.212)$ \\
\hline \multirow[t]{2}{*}{ MARRF } & -0.258 & -0.298 & 0.102 & -0.264 & 0.061 \\
\hline & $(0.085)$ & $(0.113)$ & $(0.169)$ & $(0.089)$ & $(0.287)$ \\
\hline \multirow[t]{2}{*}{ CLOSE } & 0.059 & -0.078 & -0.056 & 0.078 & -0.237 \\
\hline & $(0.044)$ & $(0.058)$ & $(0.087)$ & $(0.046)$ & $(0.150)$ \\
\hline \multirow[t]{2}{*}{ NOTICE } & 0.059 & 0.216 & -0.354 & 0.096 & -0.274 \\
\hline & $(0.064)$ & $(0.084)$ & $(0.128)$ & $(0.067)$ & $(0.204)$ \\
\hline \multirow[t]{2}{*}{ UNION } & 0.037 & -0.011 & 0.081 & 0.013 & 0.194 \\
\hline & $(0.073)$ & $(0.100)$ & $(0.145)$ & $(0.078)$ & $(0.220)$ \\
\hline \multirow[t]{2}{*}{ UR } & -0.069 & -0.064 & -0.045 & -0.086 & 0.023 \\
\hline & $(0.051)$ & (0.069) & $(0.074)$ & $(0.047)$ & $(0.063)$ \\
\hline STATE EFFECTS & YES & \multicolumn{2}{|c|}{ YES } & \multicolumn{2}{|c|}{ YES } \\
\hline Gamma parameter & a & \multicolumn{2}{|c|}{ a } & \multicolumn{2}{|c|}{ a } \\
\hline Log-likelihood & -7521.73 & \multicolumn{2}{|c|}{-7514.4} & & \\
\hline
\end{tabular}

Asymptotic |t|-statistics in parentheses

Notes: See Notes to Table 1. TIMEX denotes time to exhaustion of benefit in weeks, defined as state maximum benefit entitlement less the individual's elapsed duration of unemployment. 'AT' is the point of exhaustion of benefits, either 26 or 30 weeks. 
Appendix: Descriptive Statistics

\begin{tabular}{|c|c|c|c|c|}
\hline \multirow[b]{2}{*}{ Variable } & \multicolumn{2}{|c|}{ UB Recipients } & \multicolumn{2}{|c|}{ UB Nonrecipients } \\
\hline & Mean & STD & Mean & STD \\
\hline DURATION & 20.382 & 21.611 & 7.025 & 14.208 \\
\hline CENSORED & 0.127 & & 0.070 & \\
\hline SCHOOLING & 13.184 & 2.308 & 13.146 & 2.385 \\
\hline AGE & 40.572 & 10.022 & 36.826 & 11.057 \\
\hline TENURE & 5.782 & 6.516 & 4.073 & 6.100 \\
\hline WHITE & 0.854 & & 0.869 & \\
\hline MALE & 0.565 & & 0.560 & \\
\hline MARRIED & 0.590 & & 0.545 & \\
\hline MARRF & 0.237 & & 0.213 & \\
\hline CLOSE & 0.411 & & 0.385 & \\
\hline NOTICE & 0.142 & & 0.124 & \\
\hline UNION & 0.135 & & 0.069 & \\
\hline UR & 5.434 & & 5.168 & \\
\hline $\mathrm{n}$ & & & & \\
\hline
\end{tabular}




\section{IZA Discussion Papers}

\begin{tabular}{|c|c|c|c|c|}
\hline No. & Author(s) & Title & Area & Date \\
\hline 963 & $\begin{array}{l}\text { L. Diaz-Serrano } \\
\text { J. Hartog } \\
\text { H. S. Nielsen }\end{array}$ & $\begin{array}{l}\text { Compensating Wage Differentials for } \\
\text { Schooling Risk in Denmark }\end{array}$ & 5 & $12 / 03$ \\
\hline 964 & $\begin{array}{l}\text { R. Schettkat } \\
\text { L. Yocarini }\end{array}$ & $\begin{array}{l}\text { The Shift to Services: } \\
\text { A Review of the Literature }\end{array}$ & 5 & $12 / 03$ \\
\hline 965 & $\begin{array}{l}\text { M. Merz } \\
\text { E. Yashiv }\end{array}$ & Labor and the Market Value of the Firm & 1 & $12 / 03$ \\
\hline 966 & T. Palokangas & $\begin{array}{l}\text { Optimal Taxation with Capital Accumulation } \\
\text { and Wage Bargaining }\end{array}$ & 3 & $12 / 03$ \\
\hline 967 & $\begin{array}{l}\text { M. Lechner } \\
\text { R. Vazquez-Alvarez }\end{array}$ & $\begin{array}{l}\text { The Effect of Disability on Labour Market } \\
\text { Outcomes in Germany: Evidence from Matching }\end{array}$ & 6 & $12 / 03$ \\
\hline 968 & $\begin{array}{l}\text { M. Blázquez } \\
\text { M. Jansen }\end{array}$ & $\begin{array}{l}\text { Efficiency in a Matching Model with } \\
\text { Heterogeneous Agents: Too Many } \\
\text { Good or Bad Jobs? }\end{array}$ & 1 & $12 / 03$ \\
\hline 969 & $\begin{array}{l}\text { J.-P. Schraepler } \\
\text { G. G. Wagner }\end{array}$ & $\begin{array}{l}\text { Identification, Characteristics and Impact of } \\
\text { Faked Interviews in Surveys }\end{array}$ & 7 & $12 / 03$ \\
\hline 970 & $\begin{array}{l}\text { G. Kertesi } \\
\text { J. Köllõ }\end{array}$ & $\begin{array}{l}\text { Fighting "Low Equilibria" by Doubling the } \\
\text { Minimum Wage? Hungary's Experiment }\end{array}$ & 4 & $12 / 03$ \\
\hline 971 & $\begin{array}{l}\text { J. De Loecker } \\
\text { J. Konings }\end{array}$ & $\begin{array}{l}\text { Creative Destruction and Productivity Growth in } \\
\text { an Emerging Economy: Evidence from } \\
\text { Slovenian Manufacturing }\end{array}$ & 4 & $12 / 03$ \\
\hline 972 & J. Köllõ & $\begin{array}{l}\text { Transition on the Shop Floor - The Restructuring } \\
\text { of a Weaving Mill, Hungary 1988-97 }\end{array}$ & 4 & $12 / 03$ \\
\hline 973 & $\begin{array}{l}\text { C. Belzil } \\
\text { J. Hansen }\end{array}$ & $\begin{array}{l}\text { Structural Estimates of the Intergenerational } \\
\text { Education Correlation }\end{array}$ & 1 & $12 / 03$ \\
\hline 974 & $\begin{array}{l}\text { J. Schwarze } \\
\text { M. Härpfer }\end{array}$ & $\begin{array}{l}\text { Are People Inequality Averse, and Do They } \\
\text { Prefer Redistribution by the State? A Revised } \\
\text { Version }\end{array}$ & 3 & $12 / 03$ \\
\hline 975 & $\begin{array}{l}\text { A. Constant } \\
\text { K. F. Zimmermann }\end{array}$ & Occupational Choice across Generations & 1 & $12 / 03$ \\
\hline 976 & $\begin{array}{l}\text { J. D. Angrist } \\
\text { K. Lang }\end{array}$ & $\begin{array}{l}\text { Does School Integration Generate Peer Effects? } \\
\text { Evidence from Boston's Metco Program }\end{array}$ & 6 & $01 / 04$ \\
\hline 977 & $\begin{array}{l}\text { M. Corak } \\
\text { G. Lipps } \\
\text { J. Zhao }\end{array}$ & $\begin{array}{l}\text { Family Income and Participation in Post- } \\
\text { Secondary Education }\end{array}$ & 5 & $01 / 04$ \\
\hline 978 & $\begin{array}{l}\text { J. T. Addison } \\
\text { P. Portugal }\end{array}$ & $\begin{array}{l}\text { How Does the Unemployment Insurance System } \\
\text { Shape the Time Profile of Jobless Duration? }\end{array}$ & 3 & $01 / 04$ \\
\hline
\end{tabular}

An updated list of IZA Discussion Papers is available on the center's homepage www.iza.org. 